\title{
A Comparative Study on Maternal and Fetal Outcome in Cases of Placenta Previa with Previous Cesarean Section and Without Previous Cesarean Section
}

\author{
Authors \\ Dr Simi Jameela ${ }^{1}$, Dr Bindu Policarp ${ }^{2}$, Dr Uma Thankam ${ }^{3}$, Dr Nirmala Chellamma \\ ${ }^{1,3}$ Assistant Professor, ${ }^{2}$ Associate Professor \\ ${ }^{4}$ Professor and Head of the Department of Obstetrics and Gynaecology \\ Sree Avittom Thirunal Hospital, Trivandrum
}

\begin{abstract}
Placenta previa is the major cause of antepartum haemorrhage that causes serious morbidity and mortality to both fetus and mother.

Objective[s]: To compare the antepartum, intrapartum, postpartum complications in placenta previa with previous cesarean section and without previous cesarean section.

To compare the fetal outcome in the two groups of cases of placenta previa.

Materials and Methods: This is a case control study conducted in Sree Avittom Thirunal Hospital Trivandrum over a period of one year with diagnosed case of placenta previa with previous cesarean and without previous cesarean During the study period out of 14164 deliveries 190 cases of placenta previa were reported. After excluding all primi and multiple pregnancies [to avoid bias] there were 58 cases in the case group and 72 cases in the control group.

We have excluded other causes of antepartum haemorrhage and those referred as P.P.H.

Results: Present study confirmed that APH before 37 weeks and recurrent bleeding were more in cases of placenta previa with previous cesarean than those without.

PPH 2.78 times more in case group than the control

All cases of adherent placenta were in cases of placenta with previous cesarean. The need for additional operative procedures is around 3.58 times more in case group. Cesarean hysterectomy was needed for $5.17 \%$ of case group and none in control group. Intraoperative complication [5.6 times] and postoperative complications [3 times] more in case group. The number of babies admitted to IBN was 2.5 times more in the cases than control which is due to prematurity and associated complications.

Conclusion: The study shows the need to reduce the primary cesarean rate to avoid future pregnancy complications like adherent placenta and cesarean hysterectomy. The occurrence of placenta previa in a patient with previous cesarean needs to be managed in a tertiary care centre with all facilities available, for a good maternal and neonatal outcome. Early referral of these patient to a tertiary care centre is always preferable.
\end{abstract}

Keywords: Placenta previa, previous cesarean, adherent placenta 


\section{Introduction}

The placenta previa is a major cause of vaginal bleeding in late $2^{\text {nd }}$ and $3^{\text {rd }}$ trimester. The incidence of placenta previa is $0.3 \%{ }^{1}$

Classification in relation with internal os ${ }^{1}$

Total placenta previa: the internal os is completely covered by the placenta.

Partial placenta previa: internal os is partially covered by placenta.

Marginal placenta previa: placenta at the margina of os.

Low lying placenta: implantation in the lower segment in such that the placental edge doesn't reach the os and remains outside a $2 \mathrm{~cm}$ wide perimeter around the os.

Etiology of placenta previa is unknown. Condition may be multifactorial and postulated to be related to multiparity, multiple gestation. Advanced maternal age, previous cesarean, previous abortion and possible smoking, tumours distorting uterine cavity. Numerous studies have found that a previous cesarean increases the risk of placenta previa. The risk of adherent placenta increases to $11 \%, 40 \%$, and $61 \%$ with previous one, two, three cesarean section. ${ }^{2}$ Diagnosis of placenta previa and adherent placenta by trans abdominal, trans vaginal ultrasound (grey scale, colour Doppler) and MRI. ${ }^{3}$ management of placenta previa requires a team approach with high quality competent obstetrician, senior anaesthetist, neonatologist and good OT set up and ICU. Ready availability of blood and components is a must.

Women with placenta previa are at increased risk of spontaneous abortion, preterm delivery, cesarean, multiple blood transfusion and obstetric hysterectomy. There is significant perinatal mortlity in placenta previa due to prematurity. ${ }^{4}$ certain studies showed that neonatal complications include congenital anomalies, respiratory distress syndrome and anaemia. ${ }^{5}$ The perinatal mortality rate with placenta previa was $2.3 \%$.

Maternal complications associated with placenta previa are hysterectomy. anteparum haemorrhage, intrapartum and .postpartum haemorrhage, need for transfusion, septicaemia and thrombophlebitis
Maternal mortality has dropped from 5\% to $0.1 \%$ in developed countries with the development of improved medical care and facilities.

\section{Materials and Methods}

This is a case control study conducted by Department of obstetrics and gynaecology in our institution over a period of 1 year. Study conducted with all cases diagnosed as placenta previa from history and clinical examination and confirmed by ultrasound were taken. This is sub grouped in to 2 groups' placenta previa with previous cesarean and without previous cesarean. During the study period out of 14164 deliveries 190 cases of placenta previa were reported. After excluding all primi and multiple pregnancies(to avoid bias) there were 58 cases in the case group and 72 cases in the control group.so study group is all cases of placenta previa with previous cesarean who have delivered in Sree Avittom Thirunal Hospital. The control group is all cases of placenta previa without previous cesarean (multi gravida).exclusion criteria for both case and control are primi, multiple pregnancy, other causes of APH, cases of placenta previa delivered outside but admitted with PPH. Both groups were compared for duration of hospital stay previous obstetrics history and number previous cesarean, presenting complaints that lead to the termination of pregnancy, period of gestation at termination, history of placenta previa in previous pregnancy, history of antepartum haemorrhage in present pregnancy and in the number of episodes of antepartum haemorrhage and the precipitating factors and the treatment given were noted. Preterm babies injection corticosteroid for pulmonary maturity given or not were noted. The number of blood transfusion, maternal intapartum, and postpartum complication were noted. During cesarean type of previa was confirmed again. Occurrence of intra op complications including additional surgical procedures, adherent placenta and c s hysterectomy were noted. In the postop period wound infection, secondary $\mathrm{PPH}$, sepsis, thrombophlebitis were noted. Regarding babies 
IBN admission and outcome at the time of discharge were noted.

Data analysed with the help of statistician, percentage comparison done using chi square and fisher exact test. pvalue of 0.05 or less considered as statistically significant. to assess the association for certain charecteristics with the case control study odds ratio were also calculated, all the comptations were done by using computer package, SPSS-10

\section{Results}

In this study there were 58 cases in the study group and 72 cases in the control group.

Distribution according to presenting complaints

\begin{tabular}{|l|c|c|}
\hline & Case & Control \\
\hline Bleeding & $27(46.5 \%)$ & $22(30.55 \%)$ \\
\hline Labour pain & $3(5.1 \%)$ & $6(8.3 \%)$ \\
\hline Labour pain, bleeding & $5(8.6 \%)$ & $3(4.16 \%)$ \\
\hline Rupture of membrane, bleeding & $0(0 \%)$ & $2(2.77 \%)$ \\
\hline On date, past date & $0(0 \%)$ & $5(6.94 \%)$ \\
\hline Preeclampsia & $3(5.1 \%)$ & $6(8.33 \%)$ \\
\hline Iugr, oligamnios & $1(1.72 \%)$ & $2(2.77 \%)$ \\
\hline IUD & $4(6.89 \%)$ & $4(5.55 \%)$ \\
\hline Anomaly & $0(0 \%)$ & $0(0 \%)$ \\
\hline Asymptomatic & $15(25.8 \%)$ & $22(30.5 \%)$ \\
\hline Total & $58(100 \%)$ & $72(100 \%)$ \\
\hline$\chi 2-3.50 ;$ P value- $0.061 ; \quad$ OR- $1.98 \quad$ Not significant \\
\hline
\end{tabular}



Indication for termination

\begin{tabular}{|l|c|c|}
\hline & Case & Control \\
\hline Bleeding & $32[55.2 \%]$ & $27[37.5 \%]$ \\
\hline no bleeding & $26[44.8 \%]$ & $45[62.5 \%]$ \\
\hline Total & $58[100 \%]$ & $72[100 \%]$ \\
\hline
\end{tabular}

Presenting Complaints- Bleeding

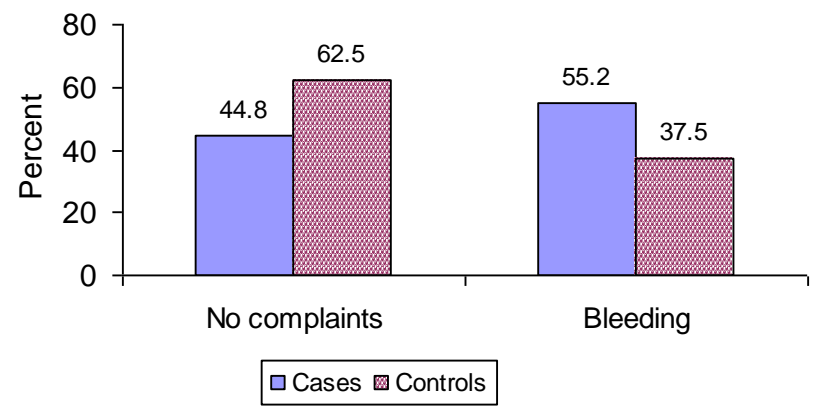

In both groups bleeding was the main presenting compliant that lead to termination of pregnancy but bleeding as an indication for termination of pregnancy was significantly (2 times) more in the case group.

Distribution according to Period of Gestation at Termination

\begin{tabular}{|l|c|c|}
\hline & Case & Control \\
\hline$\leq 37$ weeks & $40(68.9 \%)$ & $30(41.6 \%)$ \\
\hline$>37$ weeks & $18(31.1 \%)$ & $42(58.4 \%)$ \\
\hline Total & $58(100 \%)$ & $72(100 \%)$ \\
\hline
\end{tabular}

Majority terminated $\leq 37$ weeks in the case group compared to control group. It was statistically significant (3 times).

Distribution according to Antepartum

Hemorrhage

\begin{tabular}{|l|l|l|}
\hline & Case & Control \\
\hline Present & $35(60.34 \%)$ & $30(41.66 \%)$ \\
\hline Absent & $23(39.65 \%)$ & $42(58.3 \%)$ \\
\hline Total & $58(100 \%)$ & $72(100 \%)$ \\
\hline
\end{tabular}

Antepartum hemorrhage was 2 times more in case group compared to the control group.




Distribution according to Number of Episodes of APH

\begin{tabular}{|l|c|c|}
\hline Number of episodes of APH & Case & Control \\
\hline 0 & $23(39.65)$ & $42(58.35 \%)$ \\
\hline 1 & $22(37.93 \%)$ & $20(27.7 \%)$ \\
\hline 2 & $8(13.79 \%)$ & $5(6.9 \%)$ \\
\hline 3 & $4(6.89 \%)$ & $4(5.6 \%)$ \\
\hline 4 & $1(1.72 \%)$ & $1(1.4 \%)$ \\
\hline Total & $58(100 \%)$ & $72(100 \%)$ \\
\hline $2=4.48 ;$ P value- $0.034 ;$ OR $=2.13$ & Significant
\end{tabular}

APH and Recurrent episodes of APH were significantly greater in the case group (2 times) compared to the control group

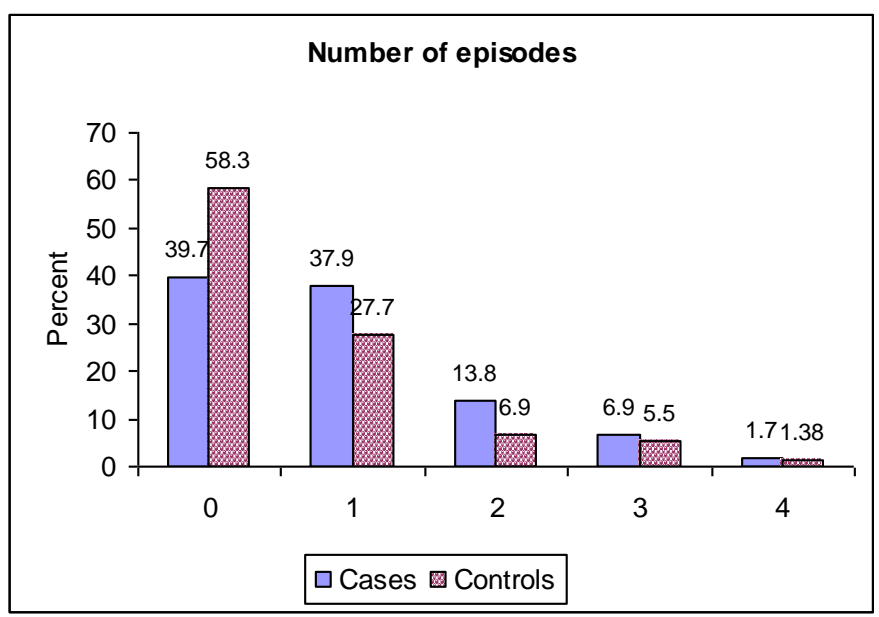

Distribution according to Blood Transfusion

\begin{tabular}{|l|c|c|}
\hline & Case & Control \\
\hline 0 & $3(5.1 \%)$ & $32(44.4 \%)$ \\
\hline$<2$ & $35(60.34 \%)$ & $38(52.7 \%)$ \\
\hline $2-4$ & $12(20.7 \%)$ & $2(2.77 \%)$ \\
\hline $4-6$ & $7(12.1 \%)$ & $0(0 \%)$ \\
\hline$>6$ & $1(1.7 \%)$ & $0(0 \%)$ \\
\hline Total & $58(100 \%)$ & $72(100 \%)$ \\
\hline
\end{tabular}

$\chi^{2}-25.18 ; P-0.000 ; O R=14.67$ Significant

Large number of blood transfusions was needed in the case group compared to the control group which was statistically significant.

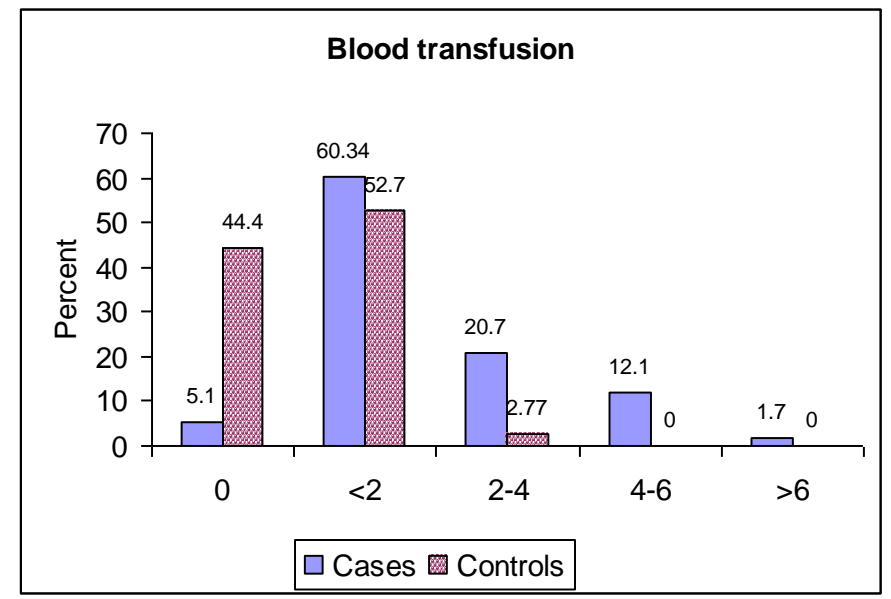

Distribution according to Mode of Delivery

\begin{tabular}{|c|c|c|}
\hline & Case & Control \\
\hline Vaginal & $0(0 \%)$ & $3(4.16 \%)$ \\
\hline $\begin{array}{l}\text { Emergency } \\
\text { cesarean }\end{array}$ & $36(62.06 \%)$ & $30(41.67 \%)$ \\
\hline Elective cesarean & $22(37.93 \%)$ & $39(54.17 \%)$ \\
\hline Total & $58(100 \%)$ & $72(100 \%)$ \\
\hline
\end{tabular}

\section{Mode of delivery}

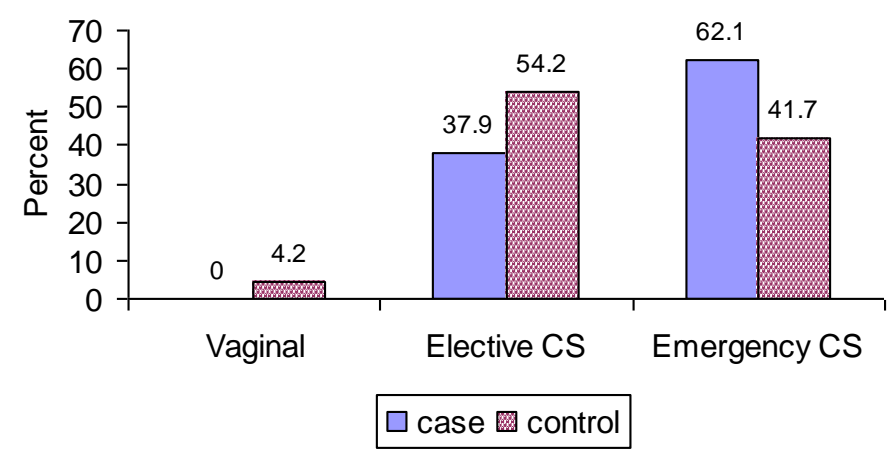

Vaginal delivery $4.16 \%$ in the control group. Emergency cesarean $62.06 \%$ in the case group compared to $43.05 \%$ in the control group. Which was statistically not significant

Distribution according to Post-Partum Haemorrhage

\begin{tabular}{|l|c|c|}
\hline & Case & Control \\
\hline Absent & $18(31.03 \%)$ & $40(55.5 \%)$ \\
\hline Present & $40(68.97 \%)$ & $32(44.5 \%)$ \\
\hline Total & $58(100 \%)$ & $72(100 \%)$ \\
\hline \multicolumn{2}{|c|}{$\chi^{2-7.82 ;} P-0.005 ;$ OR -2.78 Significant }
\end{tabular}



PPH was significantly more in the case group (2.8 times) compared to the control group. 
Distribution according to Placental Adherence

\begin{tabular}{|l|c|c|}
\hline & Case & Control \\
\hline Absent & $55(94.82 \%)$ & $72(100 \%)$ \\
\hline Present & $3(5.17 \%)$ & $0(0 \%)$ \\
\hline Total & $58(100 \%)$ & $72(100 \%)$ \\
\hline
\end{tabular}

Because of a 'Zero'

Chi squire test cannot be done

Fishers exact test $\mathrm{P}$ value $=0.094 ;$ OR cannot be calculated

Placental adherence were only found in case group.



Distribution according to Third Stage

Management

\begin{tabular}{|l|c|c|}
\hline & Case & Control \\
\hline Combination drugs needed & $23(38.5 \%)$ & $17(23.5 \%)$ \\
\hline Not needed & $35(61.5 \%)$ & $55(76.5 \%)$ \\
\hline Total & $58(100 \%)$ & $72(100 \%)$ \\
\hline$\chi 2-3.88 ; P-0.049 ;$ OR $-2.13 \quad$ Significant
\end{tabular}

Use of combination drugs needed was significantly more in the case group (38.5\%) compared to $23.5 \%$ in the control group. No drugs were needed in majority of control group (44.5\%).

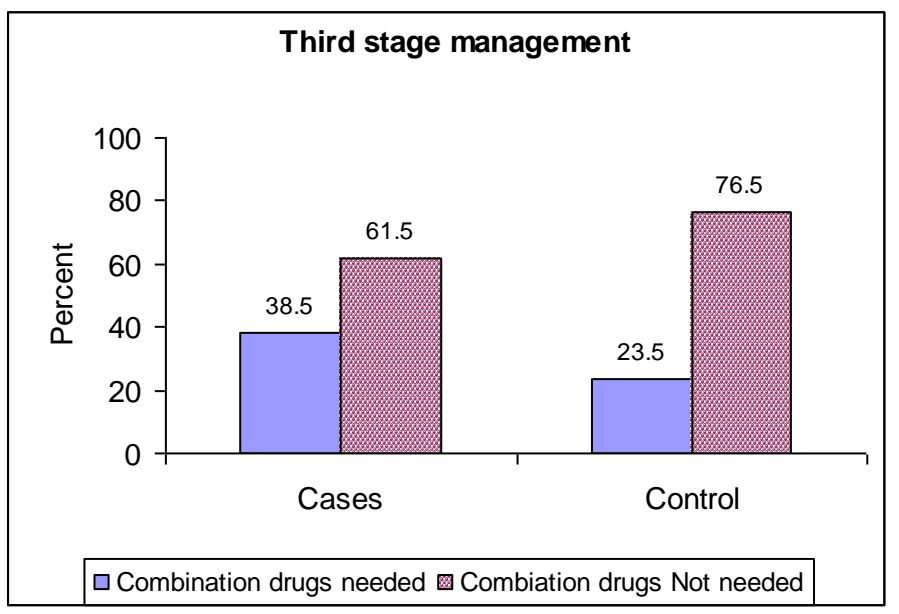

Third Stage Management

\begin{tabular}{|l|l|l|}
\hline & Case & Control \\
\hline None & $8(13.7 \%)$ & $32(44.5 \%)$ \\
\hline Methergin & $22(37.93 \%)$ & $20(27.7 \%)$ \\
\hline $\mathrm{PGF}_{2} \alpha$ & $2(3.44 \%)$ & $1(1.38 \%)$ \\
\hline PGE $_{1}$ & $3(5.17 \%)$ & $2(2.77 \% 0$ \\
\hline Combined & $23(38.5 \%)$ & $17(23.5 \%)$ \\
\hline Total & $58(100 \%)$ & $72(100 \%)$ \\
\hline
\end{tabular}

Distribution according to Need for Additional Operative Procedure

\begin{tabular}{|c|c|c|}
\hline & Case & Control \\
\hline No additional operations & $15(25.8 \%)$ & $40(55.5 \%)$ \\
\hline Needed & $43(74.2 \%)$ & $32(44.5 \%)$ \\
\hline Total & $58(100 \%)$ & $72(100 \%)$ \\
\hline
\end{tabular}

Additional operative procedures for control of PPH (3.5 times) significantly more in the case group than the control group.

Additional operative procedures

\begin{tabular}{|l|c|c|}
\hline & Case (43) & Control (32) \\
\hline Placental bed suturing & 4 & 5 \\
\hline Uterine artery ligation & 20 & 16 \\
\hline $\begin{array}{l}\text { Placental bed suturing, uterine } \\
\text { artery ligation }\end{array}$ & 11 & 10 \\
\hline $\begin{array}{l}\text { Uterine artery ligation and } \\
\text { other procedures }\end{array}$ & 8 & 1 \\
\hline
\end{tabular}

Uterine artery ligation and other procedures

\begin{tabular}{|l|c|c|}
\hline & Case & Control \\
\hline Ovarian A ligation & 1 & 1 \\
\hline Internal iliac A ligation & 3 & 0 \\
\hline B Lynch ligation & 1 & 0 \\
\hline C.S hysterectomy & 3 & 0 \\
\hline
\end{tabular}

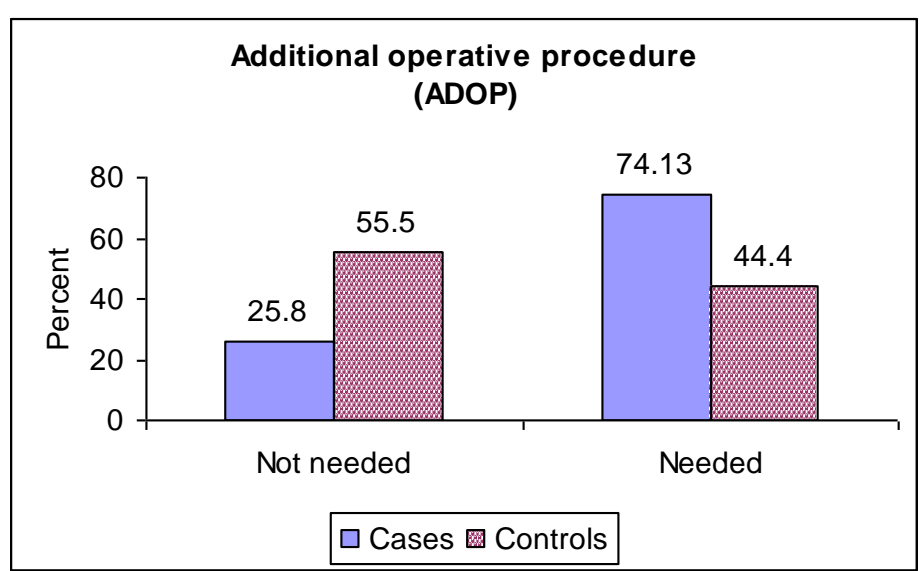

Distribution according to CS Hysterectomy

\begin{tabular}{|l|c|c|}
\hline & Case & Control \\
\hline Needed & $3(5.17 \%)$ & $0(0 \%)$ \\
\hline Not needed & $\begin{array}{c}55 \\
(94.8 \%)\end{array}$ & $72(100 \%)$ \\
\hline Total & $58(100 \%)$ & $72(100 \%)$ \\
\hline
\end{tabular}






CS Hysterectomy were only in the case group (5.17\%) compared to control group which is statistically not significant due to small sample size.

One case of placenta increta and two case of placenta accreta were there all in previous one cesarean for which CS hysterectomy was done.

Distribution according to intra op complications

Intra op complications

\begin{tabular}{|c|c|c|}
\hline & Case & Control \\
\hline Absent & $50(86.3 \%)$ & $70(97.3 \%)$ \\
\hline Present & $8(13.7 \%)$ & $2(2.7 \%)$ \\
\hline Total & $58(100 \%)$ & $72(100 \%)$ \\
\hline
\end{tabular}

Intra op complications were significantly more in the case group (5.6 times) compared to the control group. Intra op complications are more in the case group.

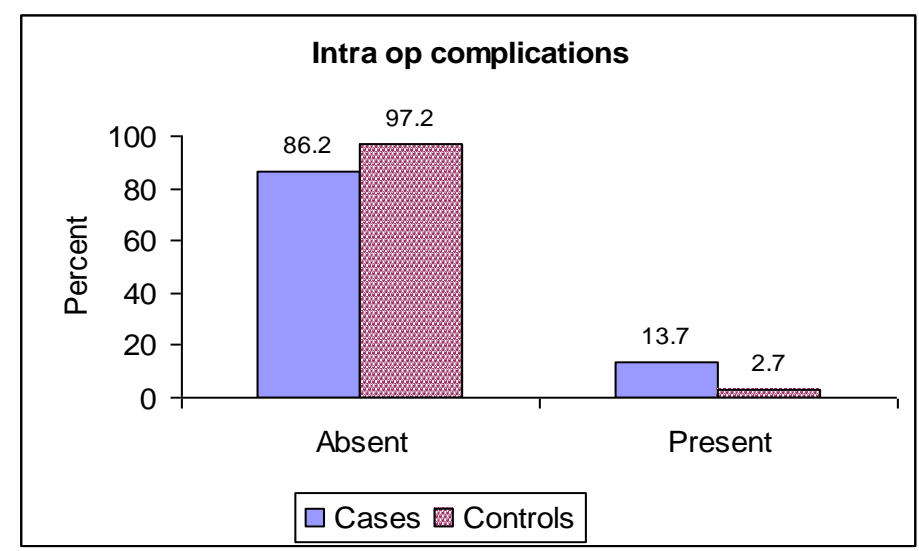

Distribution according to Birth Weight

Birth weight ( $\mathrm{kg})$

\begin{tabular}{|l|c|c|}
\hline & Case & Control \\
\hline$>=2.5$ & $35(60.34 \%)$ & $52(72.7 \%)$ \\
\hline$<2.5$ & $23(39.6 \%)$ & $20(27.3 \%)$ \\
\hline Total & $58(100 \%)$ & $72(100 \%)$ \\
\hline $2-1.72 ; \quad P-0.160 ; \quad$ not significant
\end{tabular}

Birth weight $<2.5 \mathrm{~kg}, 39.6 \%$ in the case group compared to $27.3 \%$ in the control group. But it was statistically not significant.



Distribution according to IBN Admissions IBN admissions

\begin{tabular}{|l|l|l|}
\hline & Case & Control \\
\hline No & $40(68.96 \%)$ & $61(84.7 \%)$ \\
\hline Yes & $18(31.04 \%)$ & $11(15.3 \%)$ \\
\hline$\chi 2=4.60 \quad P=.032$ OR=2.50 significant
\end{tabular}

Number of IBN admissions were significantly more in case group (2.5 times) compared to the control group.

Distribution according to Anomalies

\begin{tabular}{|l|c|c|}
\hline Anomalies & Case & Control \\
\hline Nil & $56(96.5 \%)$ & $69(95.8 \%)$ \\
\hline Present & $2(3.4 \%)$ & $3(4.1 \%)$ \\
\hline \multicolumn{2}{|c|}{ Fisher's exact test P value $=1.000$ not significant }
\end{tabular}

Anomalies were comparable in both groups, which was statistically not significant.

Distribution according to Apgar

\begin{tabular}{|l|c|c|}
\hline Apgar & Case & Control \\
\hline$<7$ & $10(17.24 \%)$ & $9(12.5 \%)$ \\
\hline$\geq 7$ & $48(82.75 \%)$ & $68(87.5 \%)$ \\
\hline
\end{tabular}

Apgar $<7$ in $17.24 \%$ in the case group compared to the $12.5 \%$ in the control group which was not statistically significant. 


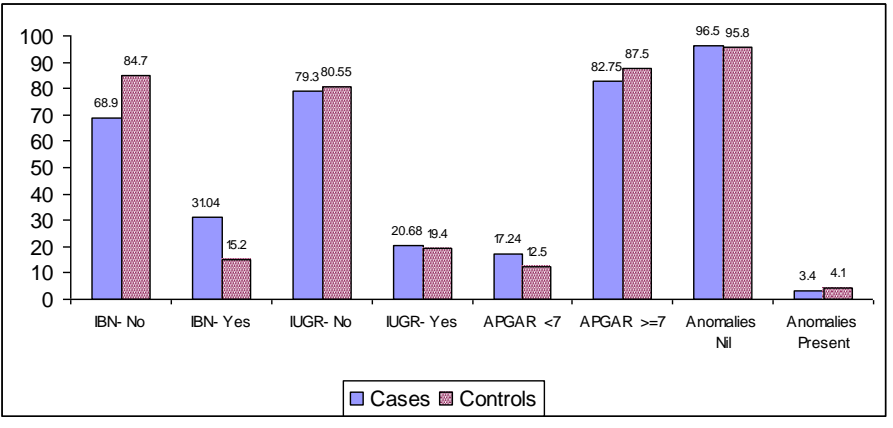

Reasons for IBN Admission

\begin{tabular}{|l|c|c|}
\hline & Case (18) & Control (11) \\
\hline Prematurity & 8 & 3 \\
\hline RDS/ HMD & 4 & 2 \\
\hline Birth asphyxia & 2 & 1 \\
\hline Infant of diabetic Mother & 1 & 1 \\
\hline MAS & 1 & 1 \\
\hline Sepsis & 1 & 1 \\
\hline Jaundice & 1 & 1 \\
\hline TTN & 0 & 0 \\
\hline HIE & 0 & 1 \\
\hline
\end{tabular}

Reason for IBN Admissions

Prematurity associated cause (RDS, HMD, NEC, and $\mathrm{ICH}$ )

\begin{tabular}{|l|c|c|}
\hline & Cases & Control \\
\hline Present & $12(20.7 \%)$ & $5(6.94 \%)$ \\
\hline Absent & $46(79.3 \%)$ & $67(93.06 \%)$ \\
\hline & \multicolumn{2}{|l}{} \\
\hline
\end{tabular}

Prematurity and associated complications were more in case group (20.6\%) compared to $6.94 \%$ in the control group, which was statistically significant.

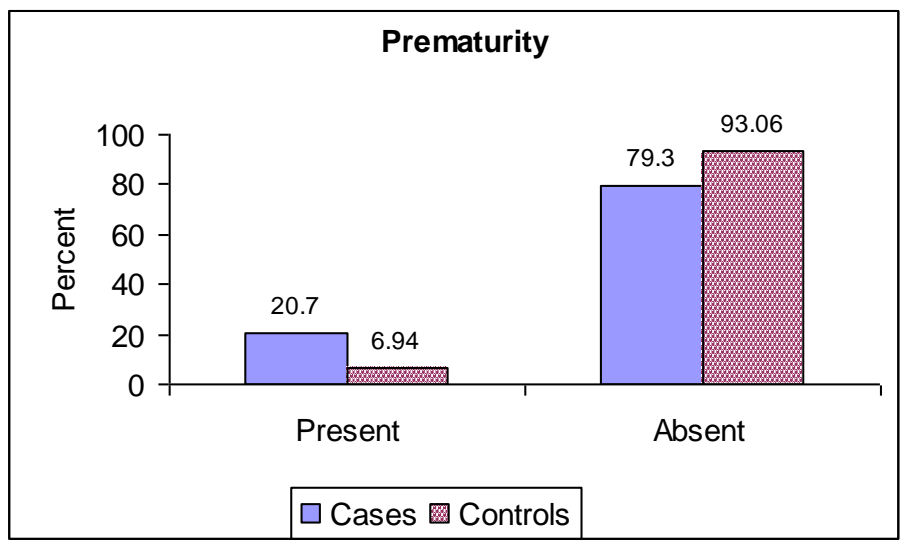

Distribution of Outcome

\begin{tabular}{|l|l|l|}
\hline & Case & Control \\
\hline Live baby & $50(86.2 \%)$ & $64(88.8)$ \\
\hline NND & $4(6.9 \%)$ & $4(5.6 \%)$ \\
\hline IUD & $4(6.9 \%)$ & $4(5.6 \%)$ \\
\hline Total & $58(100 \%)$ & $72(100 \%)$ \\
\hline
\end{tabular}

Majority were live baby in both groups. Dead babies $13.7 \%$ in the case group compared to $11.2 \%$ which was statistically not significant.

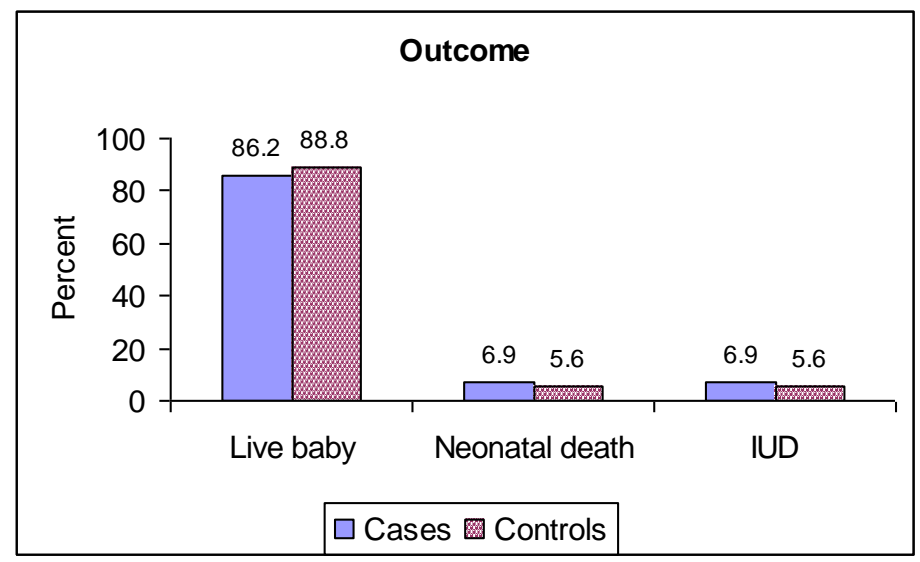

\section{Discussion}

Incidence of placenta previa and morbidly adherent placenta is on rise ${ }^{6}$ Decidual formation may be defective over a cesarean scar $^{7}$. Present study concluded the overall incidence of placenta previa in our institution is $1.34 \%$. Silver and associates reported incidence $1.3 \%$ with one previous cesarean ${ }^{8}$. Mathuriya et al study also concluded similar results ${ }^{9}$.incidence of placenta previa increases with increasing age and parity ${ }^{10}$. Getahun D et al study concluded that there is a dose response pattern in the risk of previa with increasing no of prior cesarean section and short pregnancy interval is also associated with increased risk ${ }^{11}$.study by Ihab $\mathrm{m}$ usha et al also showed increase in rate of placenta previa with increase in no of previous cesarean ${ }^{12}$.various literature concluded that increasing parity increases the risk of placenta previa ${ }^{13}$.our study included only multigravida in order to avoid biass. Placenta previa poses more risk of complications like PPH and its surgical treatments cesarean hysterectomy and operative morbidity are more in case group ${ }^{14,15}$. In present study all cases of adherent placenta seen in previous cesarean which is consistent with Clark etal study ${ }^{16}$. according to ACOG, incidence of morbidly adherent placenta is 1:2500 per delivery ${ }^{2}$.management of morbidly adherent placenta is challenging now a days,. Wong et al also found this is the most frequent indication for peri partum hysterectomy ${ }^{17}$. 
Requirement of blood and components transfusion is also significantly higher in case group ${ }^{18}$.fetal complications in terms of prematurity and its complication are more in cases of placenta previa with previous caesarean. This is because of early onset of APH and associated maternal morbidity.

\section{Conclusion}

Present study concludes that placenta previa when combines with history of previous cesarean will surely affect the outcome of both mother and foetus .cases in previous caesarean with placenta previa morbidly adherent placenta should be ruled out and it should be managed in a tertiary care centre with availability of expert high risk obstetrician, anaesthetist, paediatrician, well equipped NICU and availability of blood and components.

Finally effort should be made to reduce the cesarean section rate as it poses more risk of placenta previa, morbidly adherent placenta and its related complication in future pregnancy.

\section{References}

1. Williams obstetrics, $24^{\text {th }}$ edition, chapter 41 obstetrical haemorrhage, page 800

2. ACOG committee on obstetric practise. ACOG committee opinion number 266, Jan 2002 :placenta accrete obstet Gynecol 200299 : 169-70

3. Wong, HS, Cheung YK, Zuccolo J, et al: evaluation of sonographic diagnostic criteria for placenta accrete. J Clin Ultrasound 36[9]:551,2008

4. Salihu HM, Liq Rouse FJ et al Placenta previa: Neonatal death after live birth in US. Am J Obstet Gynaecol. 2003; 188: 1305.

5. Crane JMG, Vanden Hof MC, Dodds L. et al. Neonatal outcome with placenta previa. Obstet Gynecol. 1999; 93: 541

6. Esakoff TF,Handler S Granados JM, et al: PAMUS : placenta accrete management across the United States.J Mat Fet Neonatal Med 25;761,2012
7. Benirschke $\mathrm{K}$, Burton, Baergen $\mathrm{RN}$ : Pathology of human placenta, $6^{\text {th }}$ edition. New York, springer, 2012, p 204.

8. Morken $\mathrm{N}$ H,Henriksen $\mathrm{H}$ Placenta percreta two cases and review of literature.Eur J Obstet Gynecol Reprod Biol 2001;100;112-15

9. Mathuriya D, Lokhande P.Comparative study of obstetric outcome between scarred and unscarred uterus in placenta previa cases Indian journal of clinical practice.vol24, no6, Nov 2013.

10. Bencaiova G,Burkhardt T, Beinder; Abnormal placental invasion experience at1centre E J Reprod Med 2007 Aug52(8)709-14

11. Getahun D,Oyelese Y,Salihu H M,Ananth CV Previous caesarean delivery and risk of placenta previa and placental abruption

12. Ihab $M$,Usha MD,Elie $M$ et al placenta previa accrete risk factors and complications, American J Obtet Gynecol 2005 .193, 1045-9

13. Reddy R, Latha C. Placenta previa: an analysis of 4 year experience. J Obstet Gynaecol 2005:193: 1045-49.

14. Avan N, Benneth M J Walters WA Emergency peri partum hysterectomy; a 10 yrs. old review at Royal Hospital for women, Sydney, Aus NZ J O bstet Gynecol 51(3); 210, 2011

15. Jang DG,We JS, Shinn JU, Choi YJ, Ko HS, Park IY etal Maternal outcome according to placental position in placenta previa. Int j Med Sci 2011;8(5)439-44

16. Clark SL, Belfort MA, Carolan M, et al: Maternal death in the $21^{\text {st }}$ century: causes, prevention and relationship to caesarean delivery.AM J Obstet Gynaecol- 199: 36. $\mathrm{El}, 2008$

17. Wong TY; Emergency peri partum hysterictomy; a 10 y review in a tertiary obstetric hospital, NZ Med J124(1345);34,2011 
18. Knight M, UKOSS: Peri partum hysterectomy in UK; management and outcome of the associated haemorrhage, BJOG 114: 1380, 2007. 